Ef fect of Heat Treat ment and Transf or mat $i$ on on Bendi ng Angl e i $n$ Laser For ming of Ti tani um Foi I $s$

\begin{tabular}{|l|l|}
\hline 著者 & $\begin{array}{l}\text { OTSU Masaaki, I TO Yasuhi ro, I SHI Aki ra, M URA } \\
\text { H deshi, TAKASH MA Kazuki }\end{array}$ \\
\hline $\begin{array}{l}\text { j our nal or } \\
\text { publ i cat i on t i t I e }\end{array}$ & Key Engi neer i ng Nat er i al s \\
\hline vol une & 344 \\
\hline page range & $243-250$ \\
\hline year & $2007-04$ \\
\hline URL & ht t p: //hdl . handl e. net /10098/6394 \\
\hline
\end{tabular}




\title{
Effect of Heat Treatment and Transformation on Bending Angle in Laser Forming of Titanium Foils
}

\author{
Masaaki Otsu ${ }^{1, a}$, Yasuhiro Ito ${ }^{1, b}$, Akira Ishii, ${ }^{1, c}$ \\ Hideshi Miura $^{2, \mathrm{~d}}$ and Kazuki Takashima ${ }^{1, \mathrm{e}}$ \\ ${ }^{1}$ Department of Materials Science and Engineering, Graduate School of Science and Technology, \\ Kumamoto University, 2-39-1, Kurokami, Kumamoto, 860-8555, JAPAN \\ ${ }^{2}$ Department of Intelligent Machinery and Systems, Kyushu University, 744 Motooka, Nishi-ku, \\ Fukuoka, 819-0395, JAPAN \\ aotsu@alpha.msre.kumamoto-u.ac.jp, 'Yasuhiro_Ito@hondaeg.co.jp, \\ c057d8102@gsst.stud.kumamoto-u.ac.jp, 'miura@mech.kyushu-u.ac.jp, \\ etakashik@gpo.kumamoto-u.ac.jp
}

Keywords: laser forming, titanium foil, $\mathrm{YVO}_{4}$ laser, heat treatment, transformation, grain size

\begin{abstract}
Pure titanium foils were bent by laser forming and the effect of $\alpha-\beta$ transformation and history of heat treatment of specimen on bending angle was investigated. The thickness of specimens was changed from 40 to $100 \mu \mathrm{m}$, the length of them was $20 \mathrm{~mm}$ and the width of them was $10 \mathrm{~mm}$. The specimens were annealed at $600-1100^{\circ} \mathrm{C}$ for 30 minutes in argon atmosphere. A $20 \mathrm{~W} \mathrm{YVO}$ laser was employed and laser power was changed from 2 to $16 \mathrm{~W}$. From the experimental results, when laser power was increased, bending angle also increased and it was dramatically changed at the laser powers occurring $\alpha-\beta$ transformation and melting. Bending angle increased as grain size increased and it jumped up when grain size exceeded the foil thickness and then became constant. Bending angle decreased by annealing after forming and degree of decrease was greater when the annealing temperature before forming was lower.
\end{abstract}

\section{Introduction}

Recently, reduction of mechanical and electrical parts size is advancing and high precision is required for forming micro parts. In forming metal foils for micro parts, bending with high precision angle becomes more difficult as foil becomes thinner because of the effect of spring back.

Laser forming process is one of forming methods for sheets and foils. In this process, distributions of thermal stress and reduction of yield stress due to local rapid heating by laser irradiation is used for bending of sheets. Thus, the effect of spring back is very small and this process is suitable for bending sheets and foils. By the way, general metals appear volume change due to phase transformation when they are heated to high temperature. Although laser forming utilize distribution of volume change, it is not taken into consideration for deformation mechanisms and equations of estimating bending angle, clearly [1-2]. In order to estimate bending angle more precisely, volume change by phase transformation should be investigated.

In forming of metal parts, heat treatment is often carried out before and after forming. When heat treatment is performed before forming, microstructure such as grain size and shape, and phase change. When heat treatment is carried out after forming, phase transformation is happened, microstructure changes and residual stress disappears. Those changes by heat treatment affect to formability and shape change after heat treatment.

In this study, pure titanium foils were employed for specimen and effect of volume change by phase transformation during forming was studied. By varying laser power, bending angle was measured in the cases occurring no transformation, transformation and surface melting. Next, effect of heat treatment on formability and shape change after heat treatment was investigated. 


\section{Experimental Method}

Material. In this study, pure titanium foils with a length of $20 \mathrm{~mm}$, width of $10 \mathrm{~mm}$ and thickness of 40, 50 and $100 \mu \mathrm{m}$ were employed for specimen. They were annealed at $600^{\circ} \mathrm{C}$ for 30 minutes in argon atmosphere. Pure titanium has two crystal structures in solid state called $\alpha$ titanium having hcp structure and $\beta$ titanium having bcc structure. The $\alpha-\beta$ transformation temperature is $882.5^{\circ} \mathrm{C}$ [3]. When pure titanium is lower than this temperature, hep structure appears and if the temperature is over the temperature, $\alpha-\beta$ transformation to bcc structure is occurred and the volume increases $5.5 \%$ [4]. Melting temperature is $1668^{\circ} \mathrm{C}$ [5].

Experimental Apparatus. An experimental apparatus for laser forming and shape measurement is shown in Fig. 1. To prevent oxidizing and nitriding during forming, the specimen was put in a glass chamber with argon atmosphere. A $20 \mathrm{~W} \mathrm{YVO}_{4}$ laser which wave length is $1064 \mathrm{~nm}$ was used for laser forming. The glass chamber was fixed on a NC table. For forming, laser beam was irradiated on the specimen and scanned by galvano mirrors to perpendicular to the longitudinal direction. After forming, the glass chamber was moved to shape measuring place and bending angle was measured by a laser displacement sensor.

Experimental Procedure. First, effect of volume change by phase transformation on bending angle was investigated. Working conditions are shown in Table 1. Laser power was changed and bending angle was measured. Since the thickness of foils are very small, it was often difficult to distinguish if the transformation occurred or not from observation by optical microscope, micro vickers hardness test was also carried out.

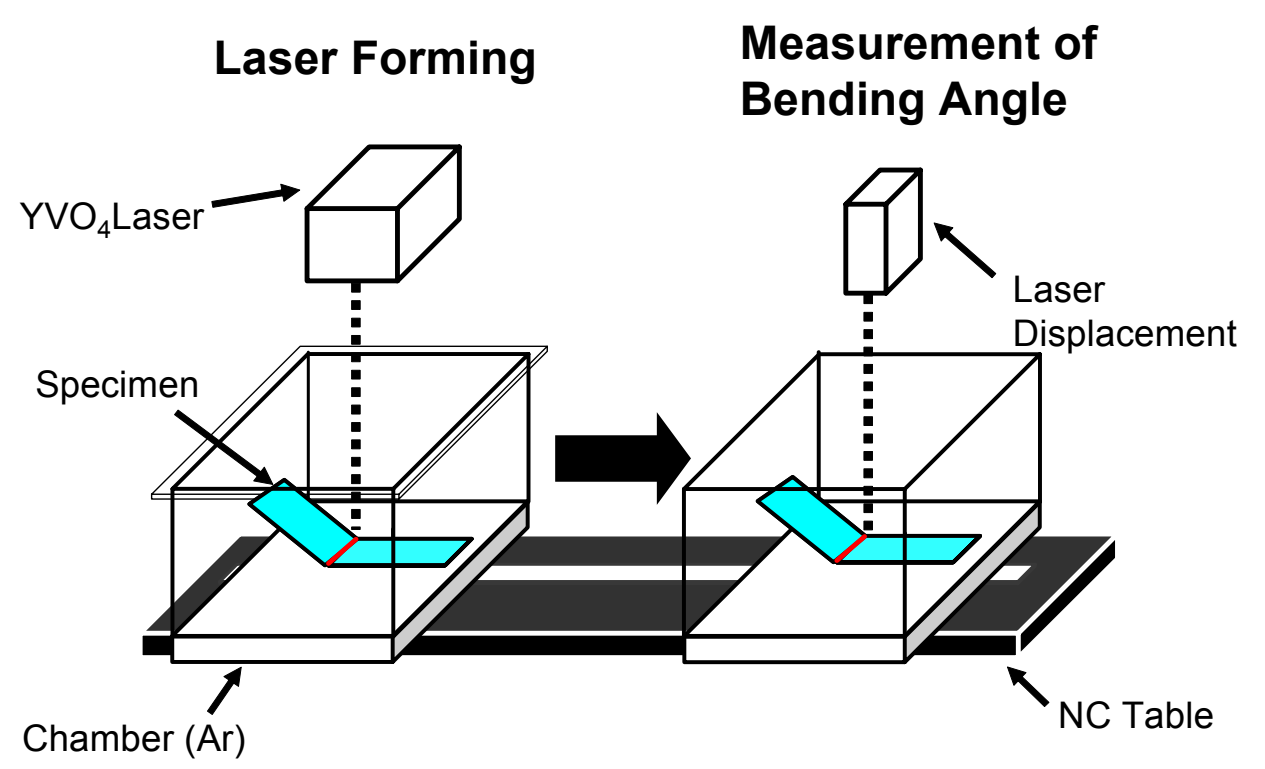

Fig. 1 Experimental set up for laser forming and measurement of bending angle.

Table 1 Working conditions for studying effect of volume change by phase transformation on bending angle.

\begin{tabular}{|c|c|}
\hline Laser device & Q-Switch pulsed $\mathrm{YVO}_{4}$ \\
\hline Wave length [nm] & 1064 \\
\hline Frequency $[\mathrm{kHz}]$ & 200 \\
\hline Laser power [W] & $2-14$ \\
\hline Laser scanning velocity [mm/s] & 10 \\
\hline Scanning number & 1 \\
\hline Forming atmosphere & $\mathrm{Ar}$ \\
\hline
\end{tabular}


Next, effect of grain size on bending angle was investigated. Heat treatment was performed before forming. Keeping time was fixed to 30 minutes and grain size of specimen was controlled by varying annealing temperature from 500 to $1100^{\circ} \mathrm{C}$. Laser forming was carried out for heat treated specimens and bending angle was measured.

Finally, effect of history of heat treatment on bending angle was studied. Recrystallized $\alpha$ titanium has equiaxed structure at room temperature. After heated up and transformed to $\beta$ titanium and cooled down to room temperature, $\alpha$ titanium shows acicular structure. Working conditions are shown in Table 2. Equiaxed (annealed at $600^{\circ} \mathrm{C}$ for 30 minutes) and acicular structures (annealed at $1000^{\circ} \mathrm{C}$ for 30 minutes) specimens were prepared. For each specimen, laser forming was carried out by changing laser power, 9.2W (not transform) and 11.0W (transform), and bending angle was measured. After forming, all specimens were annealed to have acicular structure at $1000^{\circ} \mathrm{C}$ for 30 minutes and bending angle was measured again.

\section{Results and Discussions}

\section{Effect of Volume Change by Phase Transformation.}

Hardness Change by Heat Treatment. Result of measuring hardness by changing annealing temperature is plotted in Fig. 2. When annealing temperature is lower than the $\alpha-\beta$ transformation point, $882.5^{\circ} \mathrm{C}$, equiaxed structure was appeared and hardness was less than $150 \mathrm{HV}$. As annealing temperature increased, hardness started to increase from 800 to $1000^{\circ} \mathrm{C}$ (near the transformation point) and hardness was greater than $200 \mathrm{HV}$ at more than $1000^{\circ} \mathrm{C}$. When annealing temperature was

Table 2 History of heat treatment in laser forming and annealing.

\begin{tabular}{|c|c|c|c|}
\hline & Initial annealing & Laser forming & Final annealing \\
\hline (I) & $\mathbf{E}$ & $\mathbf{E}$ & $\mathbf{A}$ \\
\hline (II) & $\mathbf{E}$ & $\mathbf{A}$ & $\mathbf{A}$ \\
\hline$(\mathrm{III})$ & $\mathbf{A}$ & $\mathbf{E}$ & $\mathbf{A}$ \\
\hline$(\mathrm{IV})$ & $\mathbf{A}$ & $\mathbf{A}$ & $\mathbf{A}$ \\
\hline
\end{tabular}

$\mathbf{E}$ : Equiaxed structure $\quad$ A: Acicular structure

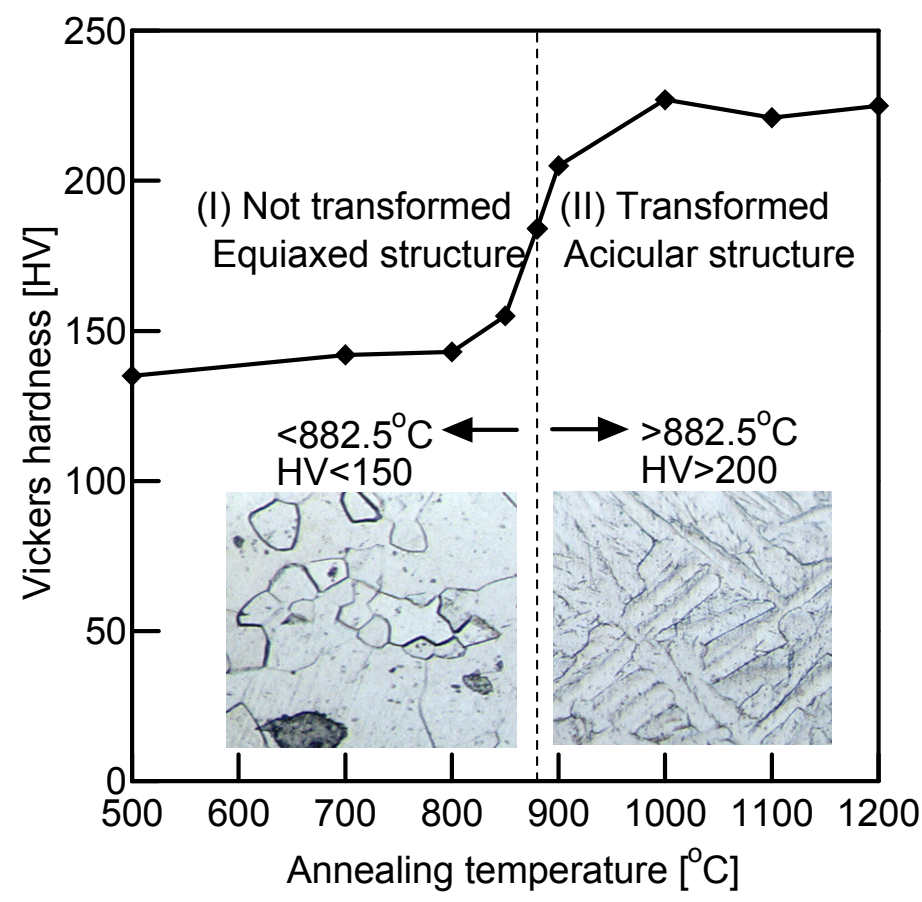

Fig. 2 Effect of annealing temperature on vickers hardness. 
higher than $882.5^{\circ} \mathrm{C}$, acicular structure was observed at room temperature. For determination of occurring $\alpha-\beta$ transformation, not only observing microstructure by an optical microscope but also result of hardness test can be used.

Laser power. Laser power was varied and occurring phase transformation was checked. Relationship between hardness and laser power is illustrated in Fig. 3. When laser power was less than $6.8 \mathrm{~W}$, hardness was lower than $150 \mathrm{HV}$ and when laser power was greater than $6.8 \mathrm{~W}$, hardness was greater than $150 \mathrm{HV}$. From this result and Fig. $2, \alpha-\beta$ transformation occurred when laser power was greater than $6.8 \mathrm{~W}$.

Fig. 4 shows the optical micrographs of cross section of formed specimen by changing laser power. Fig. 4(a) is the case when laser power is 6.0W. Phase transformation did not happened and equiaxed structure was observed. Fig. $4(\mathrm{~b})$ is the case when laser power is $7.6 \mathrm{~W}$. $\alpha-\beta$ transformation was occurred and acicular structure appeared at not only laser irradiated area but also neighboring area. In Fig. 4(c), laser power was $12.0 \mathrm{~W}$ and melting at the specimen surface was observed. When laser power was greater than $8.6 \mathrm{~W}$, surface melting was observed.

Bending angle. Relationship between bending angle and laser power is plotted in Fig. 5. From Fig. 3 and Fig. 4 , the laser powers occurring $\alpha-\beta$ transformation and surface melting were $6.8 \mathrm{~W}$ and $8.6 \mathrm{~W}$, respectively. Generally, as laser power increased, bending angle also increased gradually. But increasing rate of bending angle became larger at 6.8 and $8.6 \mathrm{~W}$ which laser powers induce $\alpha-\beta$ transformation and surface melting. The reason is considered as follows. Bending angle depends on the volume expansion at the laser irradiated area. This volume expansion induces compressive stress due to volume difference to neighboring area. Since $\alpha-\beta$ transformation or melting is occurred at only surface area, the volume difference becomes large and increasing rate of bending angle is great.

Effect of Grain Size. Fig. 6 illustrates grain size after 30 minutes annealing at various temperature. Grain size became greater as annealing temperature elevated, especially, increasing rate was high at more than $900^{\circ} \mathrm{C}$.

Effect of grain size on bending angle is plotted in Fig. 7. In this experiment, $\alpha-\beta$ transformation did not occurred when laser power was 8 and $9 \mathrm{~W}$. In these conditions, grain size did not affect to bending angle. But when laser power was greater than $10 \mathrm{~W}, \alpha-\beta$ transformation occurred, as grain

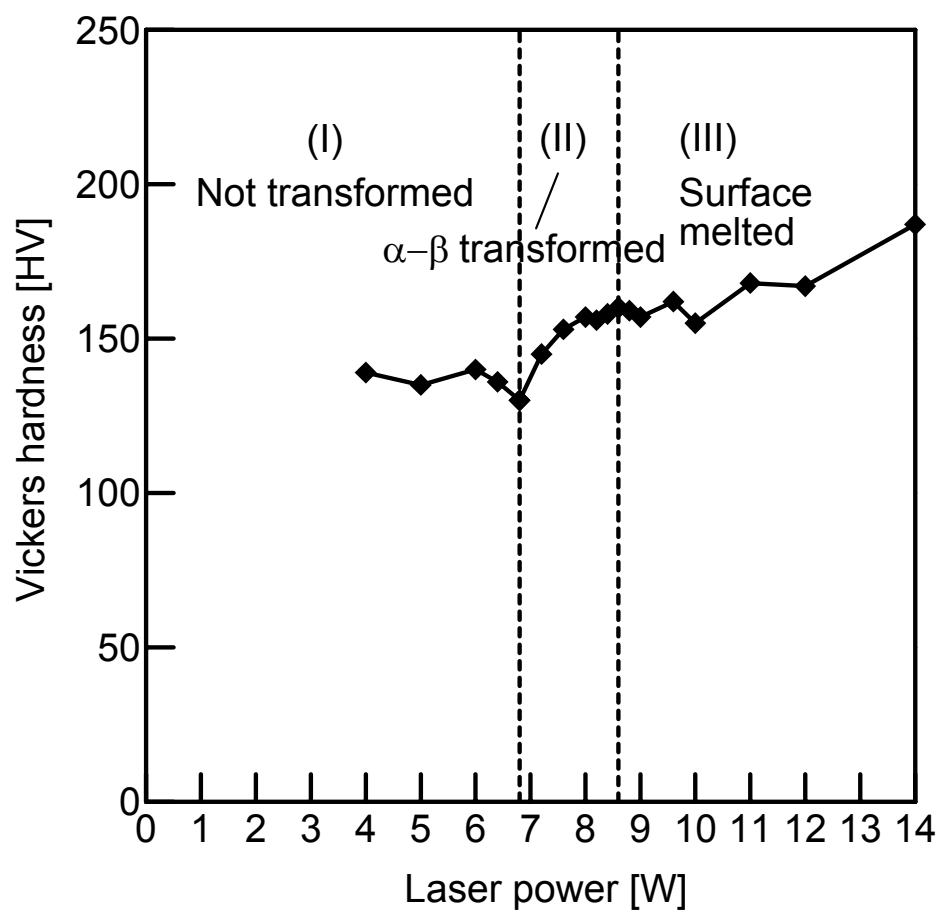

Fig. 3 Relation between hardness and laser power. 


\section{Laser irradiated area}

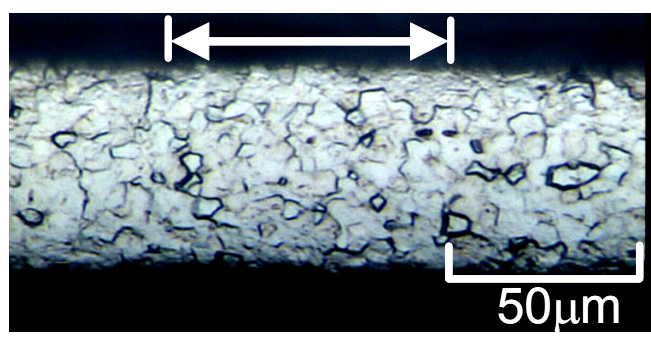

(a) (I) Not transformed (Laser power: 6.0W)

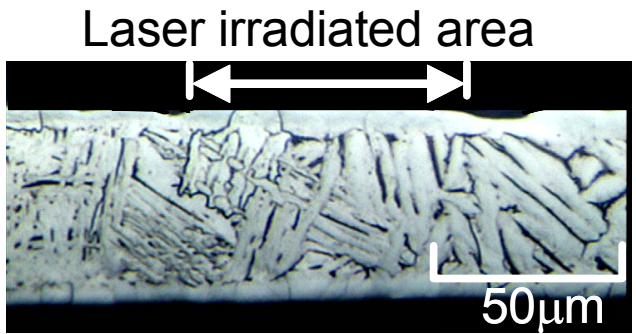

(b) (II) Transformed (Laser power: 7.6W)

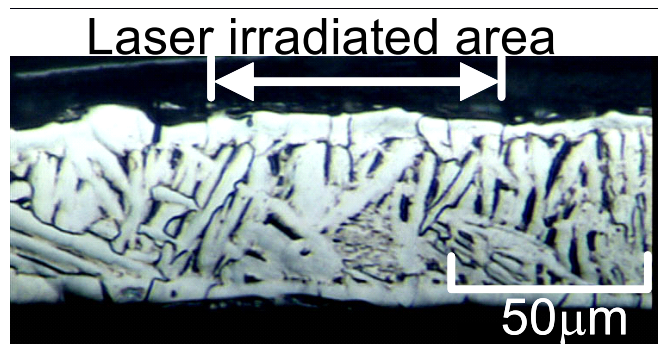

(c) (III) Partially melted (Laser power: $12.0 \mathrm{~W}$ )

Fig. 4 Cross-sectional optical micrograph of formed specimens.

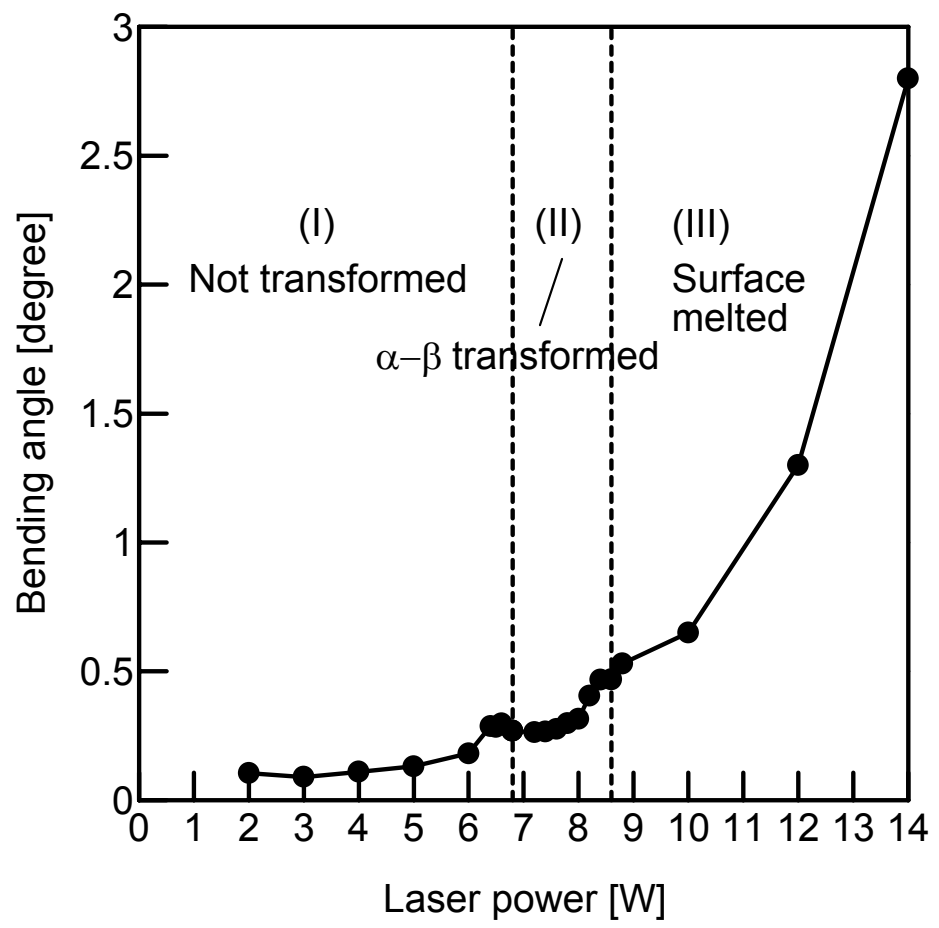

Fig. 5 Relation between bending angle and laser power. 


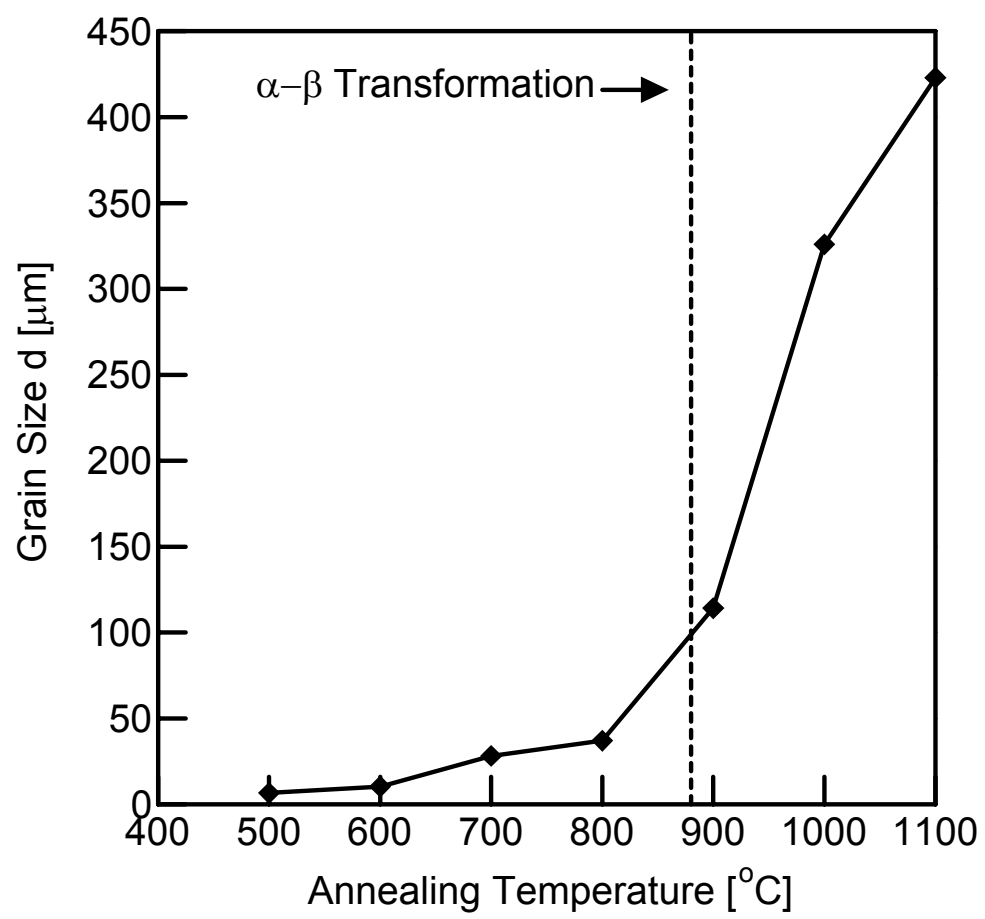

Fig. 6 Effect of annealing temperature on grain size.

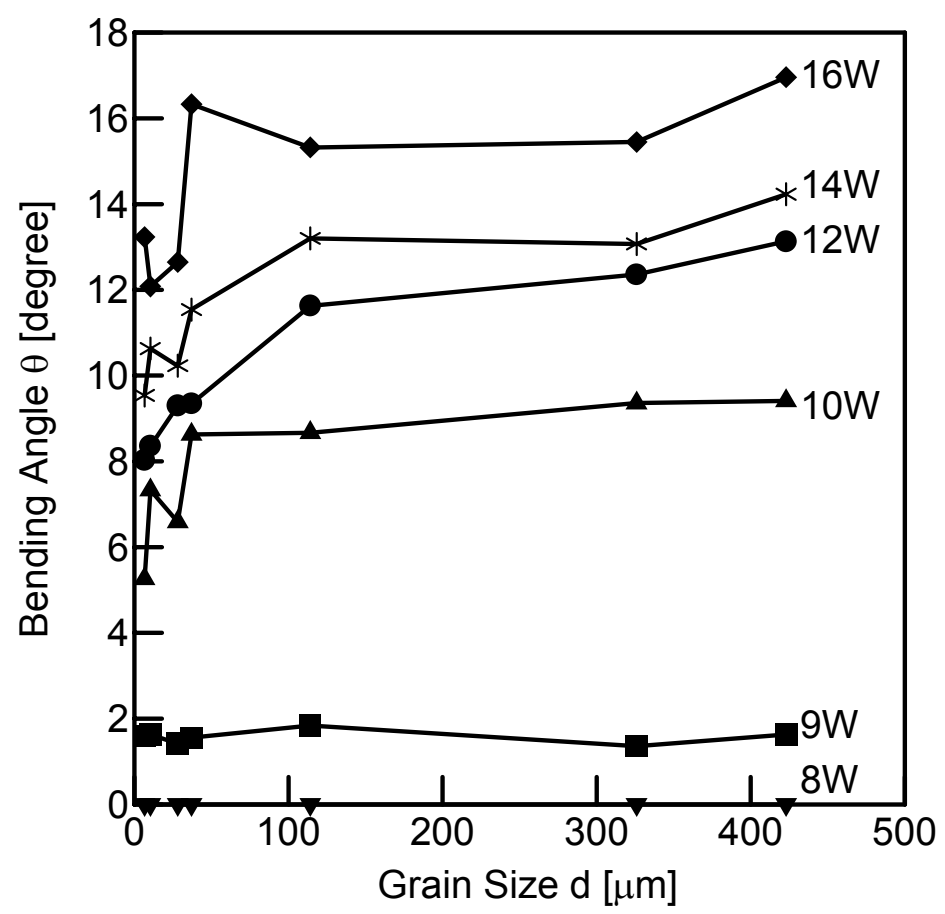

Fig. 7 Relation between bending angle and grain size with various laser power.

size increased, bending angle increased dramatically when grain size is smaller than $50 \mu \mathrm{m}$ and then became almost constant at greater than $50 \mu \mathrm{m}$.

To investigate the reason why increasing rate of bending angle changes dramatically at grain size of $50 \mu \mathrm{m}$, the same size of specimen thickness, thickness of specimen was changed. Specimens having different thickness $(40,50$ and $100 \mu \mathrm{m})$ were annealed and grain size was controlled to 50, 100 and $150 \mu \mathrm{m}$, respectively. Those specimens were formed at laser power of $9.8 \mathrm{~W}$ and the results are plotted in Fig. 8. The horizontal axis means a ratio of grain size to thickness, d/t. For every thickness, bending angle jumped up and became constant when grain size exceeded the thickness. 
Effect of History of Heat Treatment. As shown in Table 2, specimens having different structures, equiaxed and acicular structures, were prepared and formed with two different laser power, 9.2W (not transformed) and $11 \mathrm{~W}$ (transformed), and then bending angle was measured. After measuring bending angle, specimen was annealed to have acicular structure at $1000^{\circ} \mathrm{C}$ for 30 minutes and bending angle was measured again. To compare the change of bending angle between before and after heat treatment, bending angle just after forming was adjusted to about 10 degrees.

Variation of bending angle by heat treatment after forming is shown in Fig. 9. When specimens were processed to have equiaxed structure before forming, cases (I) and (II), bending angle decreased

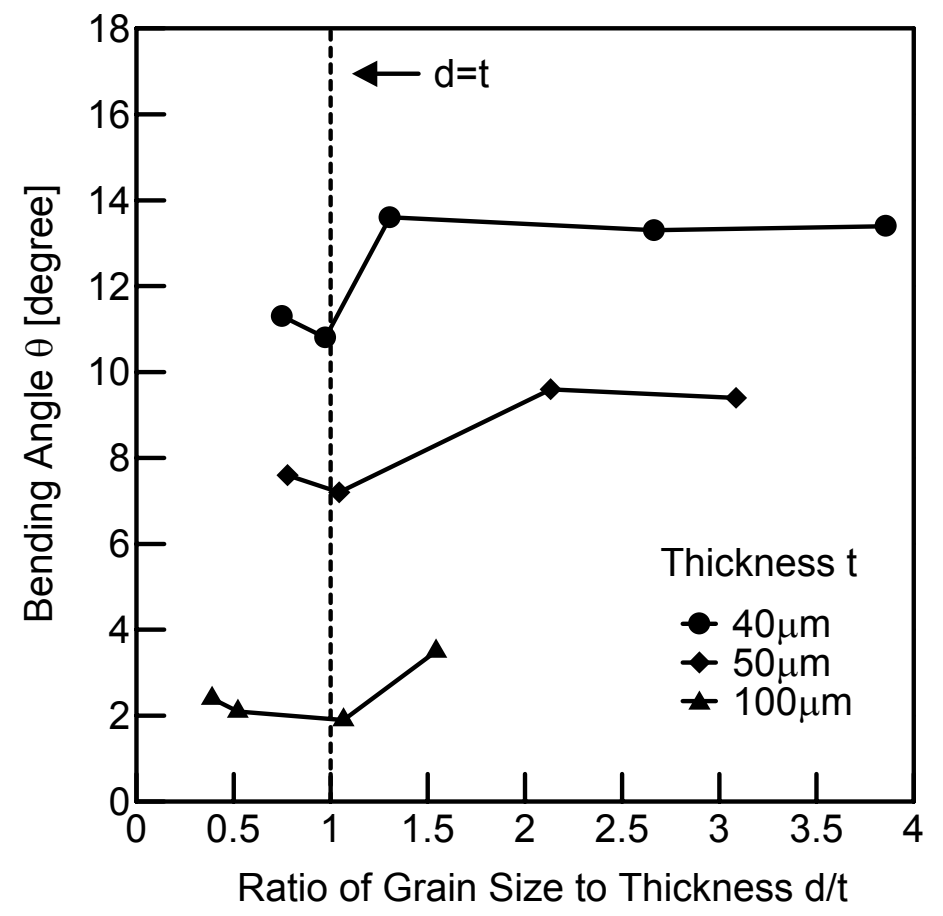

Fig. 8 Effect of ratio of grain size to thickness on bending angle.

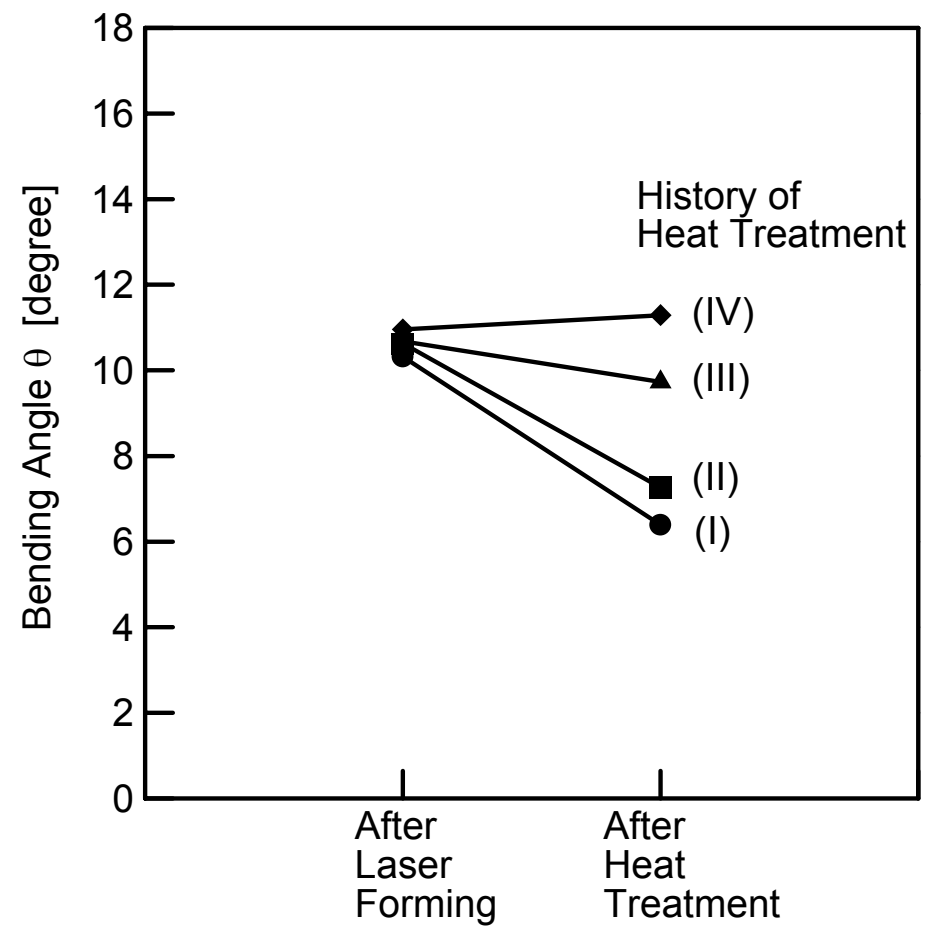

Fig. 9 Change of bending angle by heat treatment after forming. 
much after heat treatment, and when specimens annealed to have acicular structure before forming, cases (III) and (IV), bending angle did not changed or decreased a little after heat treatment.

This reason is considered as follows. Just after forming, tensile stress remains at laser irradiated part. When heat treatment is carried out after forming, recrystallization and recovery are occurred. Then residual stress is eliminated and elastic deformation is reduced and bending angle decreases. This reduction of bending angle is greater when $\alpha-\beta$ transformation is occurred. In the cases of (I) and (II), equiaxed structure transformed to acicular structure by heat treatment. Bending angle reduces much because of recrystallization, recovery, elimination of residual stress. On the other hand, in the cases of (III) and (IV), since $\alpha-\beta$ transformation does not occur by heat treatment, degree of recrystallization and recovery is small and reduction of bending angle is also small. Comparing cases (I) and (II), whole volume transforms from equiaxed structure to acicular structure in case (I), but in case (II), volume of occurring $\alpha-\beta$ transformation during heat treatment is smaller than the case (I) since formed part is already changed to acicular structure. Thus, variation of bending angle in the case (I) is larger than that of the case (II). Comparing cases (III) and (IV), in the case of (IV), laser power is enough large to happen recrystallzation and residual stress is almost eliminated just after forming, but in the case of (III), laser power is smaller than that of the case (IV) and residual stress is not eliminated enough. Thus, variation of bending angle in the case of (III) is greater than that of the case of (IV).

\section{Conclusions}

In this study, pure titanium foils was used for bending by laser forming process and effects of $\alpha-\beta$ transformation during forming, grain size of specimen and heat treatment before and after forming on bending angle were investigated and following results were obtained.

(1) When laser power increased, bending angle also increased gradually. Bending angle, however, increased dramatically at the laser powers occurring $\alpha-\beta$ transformation and melting. Thus, working conditions should be determined carefully for precise bending of foils by laser forming.

(2) As grain size became larger, bending angle also increased when grain size was smaller than the thickness of foil. When grain size was greater than the thickness of foil, bending angle was almost constant.

(3) Heat treatment conditions of before and after forming and laser power were changed to control microstructure and effect of history of heat treatment on variation of bending angle after heat treatment was studied. As volume occurring $\alpha-\beta$ transformation and recrystallization was larger, reduction of bending angle was smaller. Thus, bending angle should be a little larger by forming if heat treatment would be carried out after forming.

\section{References}

[1] F. Vollertsen: Lasers in Eng. Vol. 2 (1994), p. 261

[2] C.L. Yao, K.C. Chan and W.B. Lee: Proc. LANE'97, (1997), p. 357

[3] R.A. Higgins: Engineering Metallurgy Part I Applied Physical Metallurgy (Arnold, Great Britain 1993).

[4] Metals Handbook Committee: Metals Handbook (American Society for Metals, American Society for Metals 1952).

[5] S. Kalpakjian and S.R. Schmid: Manufacturing Engineering and Technology (Prentice-Hall Inc., United States of America 2001). 